Ege Tıp Dergisi / Ege Journal of Medicine 2020; 59 (2): 127-132

\title{
Kliniğimizde tanı almış sinonazal bölge lezyonlarının retrospektif olarak değerlendirilmesi
}

\author{
Retrospective evaluation of sinonasal lesions diagnosed in our clinic \\ Gizem Akkaş Akgün ${ }^{1}$ (D) Figen Aslan ${ }^{2}$ (D) \\ ${ }^{1}$ Kütahya Sağlık Bilimleri Üniversitesi Evliya Çelebi EAH Patoloji Anabilim Dalı, Kütahya, Türkiye \\ ${ }^{2}$ Balıkesir Tıp Fakültesi Patoloji Anabilim Dalı, Balıkesir, Türkiye
}

\section{Öz}

Amaç: Nazal kavite ve paranazal sinüslerin başlıca lezyonlarını inflamatuvar özellikteki benign lezyonlar oluştururken, malign lezyonlar oldukça nadirdir. Bu çalışmada, literatür bilgileri eşliğinde, nazal kavite ve paranazal sinüslerde kitle oluşturan lezyonların sıklığının ve dağılımlarının gözden geçirilmesi amaçlanmıştır.

Gereç ve Yöntem: Kütahya Sağlık Bilimleri Üniversitesi Evliya Çelebi Eğitim Araştırma Hastanesi Patoloji birimimizde 2013-2018 yılları arasında raporlanan 447 olguya ait, nazal kavite ve paranazal sinüslerde görülen lezyonların histopatolojik tanıları ve yerleşimleri retrospektif olarak incelendi.

Bulgular: Çalışmaya 295'i (\%65,99) erkek, 152'si (\%34,01) kadın olmak üzere 447 olgu dâhil edildi $(E / K=1,94)$. Çalışmaya dâhil edilen olguların yaş ortalaması 43,54 olarak belirlendi. Histopatolojik olarak, $6(\% 1,35)$ lezyon malign, $441(\% 98,65)$ lezyon benign olarak saptandı. Nazal polip lezyonların büyük kısmını oluşturmaktaydı (\% 82,78; 370 lezyon). Diğer benign lezyonlar: $30(\% 6,72)$ sinonazal papillom (24 inverted papillom, 6 ekzofitik papillom), $16(\% 3,58)$ piyojenik granülom, $11(\% 2,46)$ mukosel, $3(\% 0,68)$ fibrom, $2(\% 0,45)$ nazoalveolar kist, $1(\% 0,22)$ dev epidermoid kist, $1(\% 0,22)$ glomanjioperisitom, $1(\% 0,22)$ hemanjioendotelyoma, $1(\% 0,22)$ anjioleiomyom, $1(\% 0,22)$ respiratuvar epitelyal adenomatoid hamartom, $1(\% 0,22)$ osteom, $1(\% 0,22)$ fibröz displazi, $1(\% 0,22)$ fibroepitelyal polip ve $1(\% 0,22)$ hiperkeratotik aktinik keratoz olarak belirlendi. Malign lezyonlar ise $3(\% 0,68)$ malign melanom, $2(\% 0,45)$ skuamöz hücreli karsinom ve $1(\% 0,22)$ adenoid kistik karsinom olarak saptandı.

Sonuç: Sinonazal bölge lezyonları histopatojik inceleme ile benign ve malign olarak ayırt edilebilmektedir. Bu bölgedeki lezyonlar çoğunlukla benign nitelikte olup, lezyonların büyük kısmını nazal polipler oluşturmaktadır. Sinonazal bölgedeki maligniteler ise agresif tümörler olup, nadir olarak görülmektedir.

Anahtar sözcükler: Nazal patoloji, paranazal sinüs, sinonazal lezyon.

\begin{abstract}
Aim: Inflammatory benign lesions are the most common lesions of the nasal cavity and paranasal sinuses, while malignant lesions very rare. In this study, we aimed to review the frequency and distribution of lesions in the nasal cavity and paranasal sinuses with the literature.

Materials and Methods: Histopathological diagnosis and localization of lesions in nasal cavity and paranasal sinuses of 447 cases reported in our pathology unit between 2013 and 2018 were examined retrospectively in the Pathology Department of Kütahya Health Sciences University, Evliya Çelebi Education and Research Hospital.
\end{abstract}

\footnotetext{
Sorumlu yazar: Gizem Akkaş Akgün

Kütahya Sağlık Bilimleri Üniversitesi Evliya Çelebi EAH

Patoloji Anabilim Dalı, Kütahya, Türkiye

E-posta:dr.gizemakkas@gmail.com

Başvuru tarihi: 24.09.2019 Kabul tarihi: 27.01.2020
} 
Results: A total of 447 cases, 295 (65.99\%) males and 152 (34.01\%) females were included in the study (M/F = 1.94). The mean age of the cases included in the study was 43.54. Histopathologically, 6 (1.35) lesions were malignant and 441 (\%98.65) were benign. Nasal polyps were the majority of the lesions (82.78\%; 370 lesions). The other benign lesions: 30 (\%6.72) sinonasal papilloma (24 inverted papilloma, 6 exophytic papilloma), 16 (\%3.58) pyogenic granuloma, 11 (\%2.46) mucocele, 3 (\%0.68) fibroma, 2 (\%0.45) nasoalveolar cyst, 1 (\%0.22) giant epidermoid cyst, 1 (\%0.22) hemangiopericytoma, 1 (\%0.22) hemangioendothelioma, 1 (\%0.22) angioleiomyoma, 1 (\%0.22) respiratory epithelial adenomatoid hamartoma, 1 (\%0.22) osteoma, 1 (\%0.22) fibrous dysplasia, 1 (\%0.22) fibroepithelial polyp and 1 (\%0.22) hyperkeratotic actinic keratosis. Malignant lesions; 3 (\%0.68) malignant melanoma, 2 (\%0.45) squamous cell carcinoma and 1 (\%0.22) adenoid cystic carcinoma were detected.

Conclusion: Sinonasal lesions can be differentiated benign and malignant according to the histopathological examination. The lesions in this region are mostly benign and most of the lesions are nasal polyps. Sinonasal region malignancies are aggressive tumors, they are rarely seen.

Keywords: Nasal pathology, paranasal sinus, sinonasal lesion.

\section{Giriş}

Nazal kavite (NK) ve paranazal sinüslerde benign ve özellikle inflamatuvar nitelikte lezyonlar yaygınken, malign tümörler oldukça nadirdir. İnflamatuvar lezyonlar içerisinde en sık nazal polip (NP), neoplastik benign nedenler içerisinde inverted papillom (IP) (1-3), neoplastik malign nedenler içerisinde ise en sık skuamöz hücreli karsinom (SHK) gözlenmektedir (1-6).

$\mathrm{Bu}$ çalışmada, NK ve paranazal sinüslerde kitle oluşturan lezyonların sıklık ve dağılımlarının gözden geçirilmesi amaçlanmıştır.

\section{Gereç ve Yöntem}

Kütahya Sağlık Bilimleri Üniversitesi Evliya Çelebi Eğitim Araştırma Hastanesi Patoloji birimimizde 2013-2018 yılları arasında NK ve paranazal sinüslerde kitle nedeniyle operasyonları yapılmış olan 447 olgu çalışmaya alındı. Çalışmaya katılan tüm olguların patoloji arşivindeki raporlarından histopatolojik tanıları, yaş, cinsiyet ve lezyonların yerleşimleri kaydedildi. Bu bilgilerin tümüne ulaşılamayan olgular çalışma dışı bırakıldı. Değerleri ortalama ve oran olarak sunuldu.

\section{Bulgular}

Çalışmaya 295'i $\quad(\% 65,99)$ erkek, 152'si $(\% 34,01)$ kadın olmak üzere 447 olgu dahil edildi. Erkeklerin sayısı yaklaşık olarak kadınların iki katıydı (E/K=1,94). Çalışmaya dahil edilen olguların yaş ortalaması 43,54 olarak belirlendi. 447 olgunun altısı $(1,35)$ malign, 441 'i $(98,65)$ benign olarak saptandı. Lezyonların büyük çoğunluğunu NP'ler oluşturmaktaydı. Yedi İP, beş mukosel, bir malign melanom (MM), bir fibroepitelyal polip olgusuna da ikinci bir lezyon olarak NP eşlik etmekteydi. Benign olgularımızın demografik özellikleri ve lezyonların yerleşimleri Tablo-1'de özetlendi.
Malign lezyonlardan en sık MM görüldü. Malign melanom tanısı almış olan üç olgunun bir tanesine NP, diğerine ise mukosel eşlik etmekteydi. Skuamöz hücreli karsinom, ikinci sıklıkta gördüğümüz malign tümördü. Malign sinonazal lezyonların demografik özellikleri, kemik, lenfovasküler, perinöral invazyon, lenf nodu metastazı ve yerleşimleri Tablo-2'de özetlendi.

\section{Tartışma}

Literatürde ve bizim çalışmamızda en sık görülen lezyon olan NP, genellikle 40-70 yaşları arasında görülür. Yine literatürle uyumlu olarak çalışmamızda da erkek/kadın oranı 2/1'dir $(7,8)$.

Inverted papillom bizim çalışmamızda ve literatürde NK'nin en sık görülen benign tümörüydü. Bielamowicz ve ark.'nın literatürdeki 1325 olguluk seriyi değerlendirerek yaptıkları çalışmada IP'lerde erkek/kadın oranı 3/1, ortalama yaş ise 53 olarak belirtilmiştir (9). Bizim çalışmamızda ise IP olgularının yaş ortalaması 51,41 ve erkek/kadın oranı 3,8 olup bu bulgu literatürle uyumluydu. Çalışmamızda IP olgularının yedisine NP eşlik etmekteydi (\%30). Barbieri ve ark.'nın çalışmasında da iP vakalarının \%40'ına kronik sinüzit ve NP'nin eşlik ettiği bildirilmiştir (10). Bu bulgu kronik inflamasyonun hem IP hem de NP'nin etiyolojisinde önemli olabileceğini düşündürmektedir. İnverted papillomlar, benign neoplazmlar olmalarına rağmen, lokal invazyon yaparak özellikle maksillada kemik destrüksiyonu yapabilir, kafa içine ve ağız boşluğuna uzanım gösterebilirler $(3,11)$. Bizim çalışmamızda da iki olguda kafa içerisine uzanım, beyin parankimine bası ve kemik destrüksiyonu öyküsü vardı. Olgulardan birinde sert damak invazyonu ile ağız boşluğuna da uzanım mevcuttu. 
Tablo-1. Benign sinonazal lezyonların demografik özellikleri ve yerleşim yerleri.

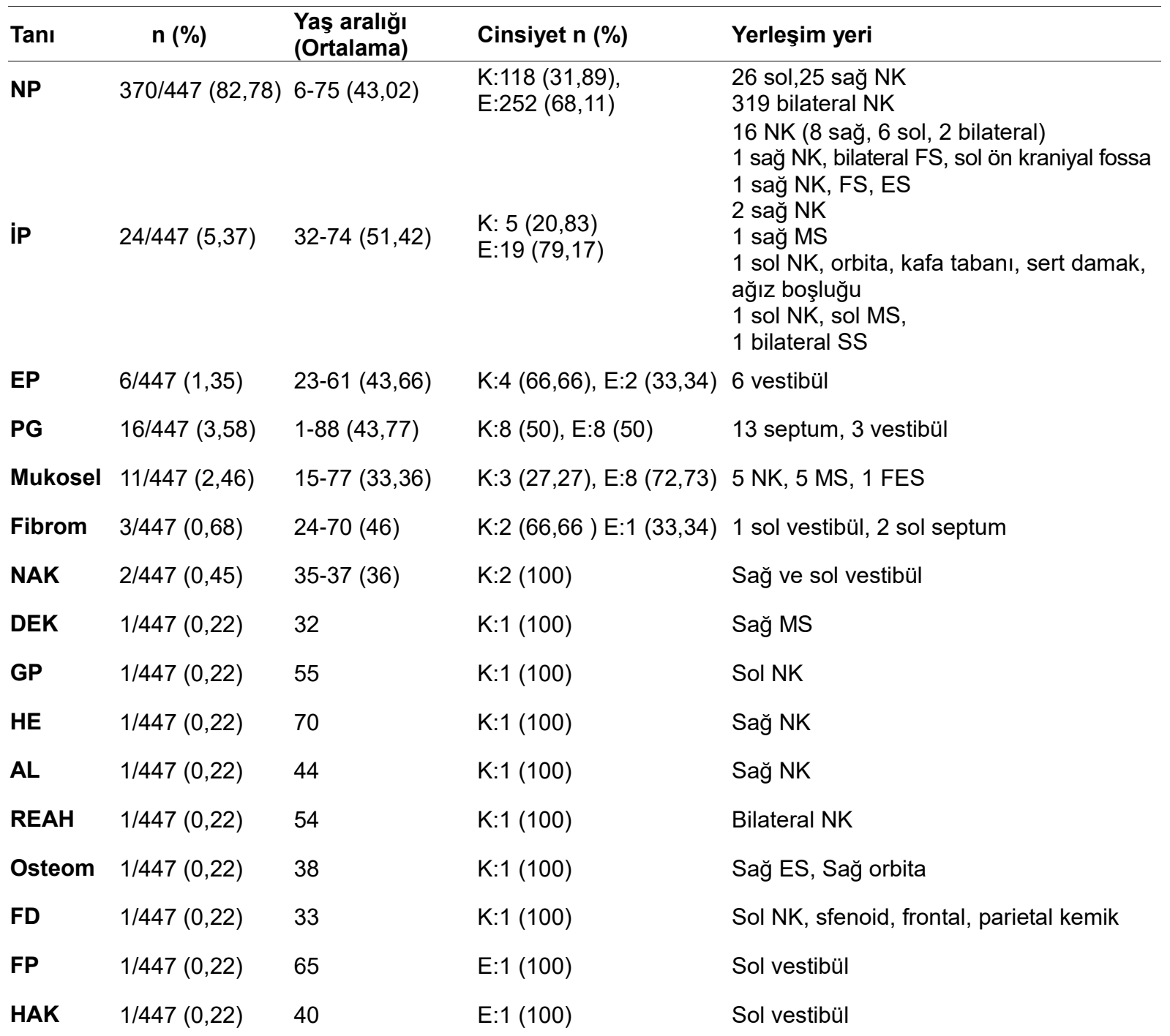

$\mathrm{NP}=$ Nazal polip, $\mathrm{IP}=$ İnverted papillom, EP= Ekzofitik papillom, $\mathrm{PG}=$ Pyojenik granülom, NAK= Nazoalveolar kist, DEK= Dev epidermoid kist, $\mathrm{GP}=$ Glomanjioperisitom, $\mathrm{HE}=$ Hemanjioendotelyom, AL=Anjioleiomyom, REAH= Respiratuar epitelyal adenomatoid hamartom, FD= Fibröz displazi, FP= Fibroepitelyal polip, HAK= Hiperkeratotik tipte aktinik keratoz, NK=Nazal kavite, $\mathrm{FS}=$ Frontal sinüs, ES=Etmoid sinüs, MS=Maksiller sinüs, $S S=S f e n o i d$ sinüs.

Tablo-2. Malign sinonazal lezyonların demografik özellikleri, kemik, lenfovasküler, perinöral invazyon, lenf nodu metastazı, yerleşimleri.

\begin{tabular}{|c|c|c|c|c|c|c|c|}
\hline Tanı & Cinsiyet & Yaş & $\begin{array}{l}\text { Kemik } \\
\text { invazyonu }\end{array}$ & $\begin{array}{l}\text { Lenfovasküler } \\
\text { invazyon }\end{array}$ & $\begin{array}{l}\text { Perinöral } \\
\text { invazyon }\end{array}$ & $\begin{array}{l}\text { Lenf nodu } \\
\text { metastazı }\end{array}$ & Lezyon Yerleşim \\
\hline MM & $\mathrm{K}$ & 67 & - & - & - & - & Sağ NK \\
\hline MM & $\mathrm{K}$ & 66 & + & - & - & - & Sağ MS \\
\hline MM & $\mathrm{K}$ & 49 & + & + & - & - & Sağ NK, Sol MS \\
\hline SHK & $E$ & 65 & + & - & + & + & NK \\
\hline SHK & $E$ & 73 & - & - & - & - & Sağ MS, sağ NK, sağ SS, orbita, cilt altı \\
\hline AKK & $E$ & 57 & + & - & + & + & Bilateral NK, MS'ler \\
\hline
\end{tabular}

$\mathrm{MM}=$ Malign Melanom, SHK= Skuamöz hücreli karsinom, AKK=Adenoid kistik karsinom, NK=Nazal kavite, MS= Maksiller sinüs, SS= Sfenoid sinüs. 
Ekzofitik papillom da daha çok nazal septum yerleşimlidir ve erkek/kadın oranı 10/1'dir. Bizim çalışmamızda ekzofitik papillom olgularının tamamı nazal vestibül yerleşimli, erkek/kadın oranı $1 / 2$ olup literatürle uyumlu değildi.

Nadiren NK'da yerleşim gösteren pyojenik granülom, kadın ve erkeklerde eşit oranda görülür ve her yaşta izlenebilir $(3,12)$. Bizim olgularımızın yaş aralığı 1-88 olup kadın ve erkek sayısı birbirine eşitti.

Mukosel, en sık frontal sinüste görülen benign lezyondur, kemik destrüksiyonu ve bası semptomları yapabilmektedir (13). Bizim çalışmamızda en sık NK ve maksiller sinüs yerleşimli olarak görüldü. Olguların beşine ikinci bir lezyon olarak NP eşlik etmekteydi. NP ve mukoselin birlikte görülme insidansının yıllık 2,5/100 olgu olduğu tahmin edilmektedir (14).

Fibromlar, septum ve vestibülde yerleşmeye eğilimlidirler. Fibrom olgularımızın biri sol nazal vestibül, diğer ikisi sol septum yerleşimli olarak görüldü.

Nazoalveolar kist, genellikle 40-50'li yaşlarda görülür ve K/E oranı 4'dür. Sıklıkla üst dudak ve nazal vestibülde yerleşir (15). Çalışmamızda 35 ve 37 yaşlarında iki kadın olguda ve biri sağ, diğeri sol nazal vestibülde izlendi.

Dev epidermoid kist ise oldukça nadirdir. Literatürdeki olgulardan biri maksillada izlenmiş olup olgunun öncesinde cerrahi öyküsünün olması lezyonun postoperatif komplikasyon olarak gelişmiş olabileceğini akla getirmiştir (16). Bizim olgumuzda da maksiller sinüs yerleşimliydi ancak geçirilmiş cerrahi öyküsü yoktu.

Glomanjioperisitom, tüm sinonazal bölge neoplazilerinin \%0,5'den daha azını oluşturur (3). Yetmişli yaşlarda daha sıktır ve hafif kadın baskınlığı vardır (3). Bizim olgumuz 55 yaşında kadındı.

Nazal kavitede oldukça az olgusu bildirilmiş olan hemanjioendotelyomanın ise genellikle genç erişkinlerde daha fazla görülmesi beklenirken (17) bizim olgumuz 70 yaşındaydı. Kadınlarda hafif oranda daha fazla görüldüğü literatürde bildirilmiştir (17).

Genellikle uterus yerleşimli olan anjioleiomyomlar, baş boyun bölgesinde nadiren görülür. Matsuyama ve ark. yaptığı 122 serilik bir çalışmada sadece dört vaka nazal kavite yerleşimlidir $(\% 3,27) \quad(18)$. Dördüncü-beşinci dekatta, kadınlarda daha sıktır (19). Bizim olgumuz 44 yaşında kadındı.
Respiratuar epitelyal adenomatoid hamartom, NK'da oldukça nadirdir (20). Nazal kavitede ise daha çok posterior nazal septumda görülür (21). Genelde genç erkeklerde görülen bu lezyonun etiyolojisinde kronik rinosinüzit vardır. Bizim olgumuz 54 yaşında kadındı ve beraberinde kronik rinosinüzit bulguları izlendi.

Osteomlar, sıklıkla frontal sinüs yerleşimlidir ve orbita yayılımı tüm orbital tümörlerin \%0,9-5,1'ini oluşturur (22). Etmoid sinüs yerleşimli olanlarında orbital yayılım daha sıktır (22). 38 yaşında erkek olan olgumuzda lezyon orbita içerisine uzanım göstermekteydi ve literatürle uyumlu olarak bu lezyon da etmoid sinüs yerleşimliydi.

Fibröz displazi, baş boyun bölgesinde en sık maksilla ve mandibulada görülür. Genelde genç erişkin ve adolesanda, hafif erkek baskınlığı olan bir lezyondur (23). Çalışmamızda bu lezyon 33 yaşında kadın olguda solda sfenoid kemiği, frontal kemiği, parietal kemiği ve NK'yı tutan kitle şeklindeydi.

Fibroepitelyal polip de NK'da oldukça nadirdir. Literatürde ilk olgu Fırat ve ark. tarafından bildirilmiş ve bugüne kadar 12 olgu tanımlanmıştır (24). Çoğu erkeklerde ve 40-70'li yaşlarda görülür. Çalışmamızda ise 65 yaşında erkek olguda izlenmiş olup sol vestibulum yerleşimliydi ve bilateral NP'lere eşlik etmekteydi.

Hiperkeratotik tipte aktinik keratoz, burnun dış yüzünde sık görülmesine karşın, NK içerisinde oldukça nadirdir. Çalışmamızda 40 yaşında erkek olguda, sol nazal vestibülde izlendi.

Sinonazal bölgenin malign tümörleri tüm malign tümörlerin $\% 0,2-0,8$ ' $\mathrm{i}$ ve baş-boyun malignitelerinin ise sadece \%3'ünü oluşturmaktadır (2). Amerika Birleşik Devletleri'nde Ulusal Kanser Enstitüsü'nün Gözetim, Epidemiyoloji ve Bitiş Sonuçları (SEER) geniş serili çalışmasında $(n=6739)$ en sık görülen malign tümör SHK $(\% 51,6)$, bunu adenokarsinom $(\% 12,6)$, olfaktör nöroblastom $(\% 6,3)$, AKK $(\% 6,2)$, MM $(\% 6,6)$ ve sinonazal andiferansiye karsinom $(\% 3,1)$ izlemektedir (5). Bizim çalışmamızda ise en çok MM (3/6) izlenmekte olup bunu SHK (2/6) ve AKK (1/6) takip etmekteydi. Çalışmamızdaki literatürle olan bu farklılığın malign olgu sayımızın azlığından kaynaklandığını düşünmekteyiz. Yine pek çok çalışmada NK'nın en çok malign tümör yerleşke alanı olduğu, bunu maksiller ve etmoid sinüsün izlediği, sfenoid sinüste ise oldukça nadir tümör geliştiği gösterilmiştir (5). Bizim çalışmamızda da 
literatürle uyumlu olarak NK en yaygın malign tümör yerleşke alanı iken, bunu maksiller sinüs izlemekteydi.

Malign melanom, malign olgularımızın \%50'sini (3/6) oluşturmaktaydı. Sinonazal mukozal MM'ler, tüm baş boyun melanomlarının yaklaşık \%4'ü ve tüm sinonazal malignitelerin ise yaklaşık \%3,5'unu oluşturur (25). Büyük bir çoğunluğu ise nazal septum yerleşimlidir. Bizim çalışmamızda da olguların iki tanesi sağ NK yerleşimli iken, biri sağ maksiller sinüs yerleşimliydi. E/K oranı $3 / 2$ olup $50-70$ yaş arası ortaya çıkar (26). Çalışmamızda bu lezyon 49, 66 ve 67 yaşlarında üç kadın olguda izlendi.

Skuamöz hücreli karsinom tüm baş boyun kanserlerinin \%3-5'ini oluşturur. Ortalama görülme yaşı 55-65 olup 40 yaştan önce nadirdir ve erkeklerde çok daha yaygındır (27). Bizim çalışmamızda literatürle uyumlu olarak olgulardan biri 65 yaşında erkek, diğeri 73 yaşında erkekti.

Adenoid kistik karsinom baş boyun bölgesinde en çok tükürük bezlerinde görülür ve sinonazal bölgede yerleşimi nadirdir. Adenoid kistik karsinom, erkeklerde hafif oranda daha yaygın olup (1,3:1) tipik olarak 40-60 yaş arasında görülür (28). Bizim olgumuz da 57 yaşında erkekti. Tanıda da önemli bir kriter olan perinöral yayılım özelliği, sinonazal bölge tümörlerinde sık görülür $(>\% 50)$ ve intrakraniyal yayılım riskini artırır (29). Bizim olgumuzda fokal perinöral invazyon ve kemikte destrüksiyon izlendi.

\section{Sonuç}

Sinonazal bölge lezyonlarının büyük çoğunluğu benign nitelikte olup olguların büyük kısmı NP'den oluşmaktadır. En sık görülen neoplastik benign lezyonu ise İP'dir.

Sinonazal bölge maligniteleri oldukça nadir ve agresif tümörlerdir. Malign sinonazal lezyonlardan en sık görüleni ise literatürde SHK iken, bizim çalışmamızda MM'dir.

Malign tümörlerle inflamatuvar lezyonların ayırımı, ancak lezyonun eksizyon materyalinin histopatolojik incelemesiyle yapılabilir.

Çıkar çatışması: Yazarlar çıkar çatışması beyan etmemişlerdir.

\section{Kaynaklar}

1. Ogle OE, Weinstock RJ, Friedman E. Surgical anatomy of the nasal cavity and paranasal sinuses. Oral Maxillofac Surg Clin North Am 2012; 24: 155-66.

2. Rosai J. Nasal cavity, paranasal sinuses and nasopharnyx. In: Rosai J (ed) Rosai and Ackerman's Surgical pathology. Vol 1, 10th Philadelphia; Mosby Elsevier; 2011: 291-306.

3. Slootweg PJ, Chan JKC, Stelow EB, Thompson LDR. Tumors of the nasal cavity, paranasal sinuses and skull base. In: El-Naggar AK, Chan JKC, Grandis JR, Takata T, Slootweg PJ (ed) WHO Classification of tumors, Pathology and Genetics of Head and Neck Tumors. Vol 9, 4rd ed. Lyon: IARC Press. 2017: 11-61.

4. Kaplan BA, Kountakis SE. Diagnosis and pathology of unilateral maxillary sinus opacification with or without evidence of contralateral disease. Laryngoscope 2004; 114 (6): 981-5.

5. Turner JH, Reh DD. Incidence and survival in patients with sinonasal cancer: a historical analysis of population-based data. Head Neck 2012 Jun;34 (6): 877-85.

6. Dulguerov P, Jacobsen MS, Allal AS, Lehmann W, Calcaterra T. Nasal and Paranasal Sinus Carcinoma: Are We Making Progress? A Series of 220 Patients and a Systematic Review. Cancer 2001 Dec 15; 92 (12): 3012-29.

7. Akbay E, Ozgur T, Cokkeser Y. Is There Any Relationship Between the Clinical, Radiological and Histopathologic Findings in Sinonasal Polyposis. Turk Pathology Derg 2013; 29 (2): 127-33.

8. Settipane GA, Lund VJ, Bernstein JM, Tos M. Nasal Polyps: Epidemiology, Pathogenesis and Treatment. Vol 1, 1 st (ed) Rhode Island: Ocean Side Pub 1997: 7-15.

9. Bielamowicz S, Calcaterra TC, Watson D. Inverting papilloma of the head and neck: the UCLA update. Otolaryngol Head Neck Surg 1993 Jul; 109 (1): 71-6.

10. Barbieri PG,Tomenzoli D, Morassi L, Festa R, Fernicola C. Sinonasal inverted papillomas and occupational etiology. G Ital Med Lav Ergon. 2005 Oct-Dec; 27 (4): 422-6. 
11. Piva MR, Santos Tde S, Martins Filho PR, Kumar PN, Souza LM, Silva LC. Inverted papilloma (Schneiderian papilloma) with involvement of the oral cavity: report of an unusual case. An Bras Dermatol. 2011 Jul-Aug; 86 (4): 779-83.

12. Smith SC, Patel RM Lucas DR, and McHugh JB. Sinonasal Lobular Capillary Hemangioma: A Clinicopathologic Study of 34 Cases Characterizing Potential for Local Recurrence. Head Neck Pathol. 2013 Jun; 7 (2): 129-34.

13. Neville B, Damm D, Allen C, Bouquot J. Oral and maxillofacial pathology. Philadelphia, PA, WB Saunders Company; 1995: 267-9.

14. Chobillon MA, Jankowski R. Relationship between mucoceles, nasal polyposis and nasalisation. Rhinology 2004 Dec; 42 (4): 219-24.

15. K el-Din, A A el-Hamd. "Nasolabial cyst: a report of eight cases and a review of the literature," $J$ Laryngol Otol 1999 Aug;113 (8): 747-9.

16. Erisir F, Kazikdaş KC, Tuna Yalcinozan E. Giant Epidermoid Cyst of the Maxillary Sinus: A Postoperative Complication? J Craniofac Surg 2018 Sep; 29 (6): 607-8.

17. Patnayak R, Jena A, Reddy MK, Chowhan AK, Rao LC, Rukhamangadha N. Epithelioid Hemangioendothelioma of Nasal Cavity. J Lab Physicians 2010 Jul-Dec; 2 (2): 111-3.

18. Matsuyama A, Hisaoka $M$, Hashimoto $H$. Angioleiomyoma: a clinicopathologic and immunohistochemical reappraisal with special reference to the correlation with myopericytoma. Hum Pathol. 2007 Apr; 38 (4): 645-51.

19. Arruda MM, Monteiro DY, Fernandes AM et al. Angioleiomyoma of the nasal cavity. Int Arch Otorhinolaryngol. 2014 Oct; 18 (4): 409-11.

20. Fitzhugh VA, Mirani N. Respiratory epithelial adenomatoid hamartoma: a review. Head Neck Pathol 20082 (3): 203-8.

21. Rom D, Lee M, Chandraratnam E, Chin R, Sritharan N. Respiratory Epithelial Adenomatoid Hamartoma: An Important Differential of Sinonasal Masses. Cureus. 2018 17; 10 (4): 2495.

22. Gökçeer T, Noshari HK, Naiboğlu B, Atbaş A. Orbital yayılımlı etmoid sinüs osteomu. Kulak Burun Bogaz Ihtis Derg 2003; 10 (3): 117-20.

23. Tsai TL, Ho CY, Guo YC, Chen W, Lin CZ. Fibrous dysplasia of the ethmoid sinus. J Chin Med Assoc 2003; 66: 131-3.

24. Fırat Y, Durgun Y, Kızılay A, Selimoğlu E. Nazogastrik Sondanın Nadir Gözlenen Bir Komplikasyonu: Intranazal Fibroepitelyal Polip KBB ve BBC Derg 2008; 16: 78-81.

25. Conley JJ. Melanomas of the mucous membrane of the head and neck. Laryngoscope 1989; 99: 1248-54.

26. Altuntaş EE, Elagöz Ş, Özer H, Uysal İ̈, Müderris S. Kliniğinimizde tanı almış benign ve malign nazal patolojili olguların retrospektif olarak değerlendirilmesi. Cumhuriyet Tıp Derg 2009; 31: 393-400.

27. Ansa $B$, Goodman $M$, Ward $K$ et al. Paranasal sinus squamous cell carcinoma incidence and survival based on surveillance, epidemiology, and end results data, 1973 to 2009. Cancer.2013; 119 (14): 2602-10.

28. Husain Q, Kanumuri VV, Svider PF et al. Sinonasal adenoid cystic carcinoma: systematic review of survival and treatmant strategies. Otolaryngol Head Neck Surg. 2013; 148 (1): 29-39.

29. Gil Z, Carlson DL, Gupta A et al.Patterns and incidence of neural invasion in patients with cancers of the paranasal sinuses. Arch Otolaryngol Head Neck Surg. 2009; 135 (2): 173-9. 